\title{
Radical C-H-Amination of Heteroarenes using Dual Initiation by Visible Light and Iodine
}

\author{
Nicola Lucchetti, ${ }^{a}$ Anastasia Tkacheva, ${ }^{a}$ Serena Fantasia, ${ }^{\mathrm{b}}$ and Kilian Muñiz ${ }^{\mathrm{a}, \mathrm{c} *}$ \\ Institute of Chemical Research of Catalonia (ICIQ), The Barcelona Institute of Science and Technology, 16 Avgda. Països \\ Catalans, 43007 Tarragona, Spain. Email: kmuniz@iciq.es \\ F. Hoffmann-La Roche Ltd. Process Research \& Development, Grenzacherstrasse 124, isepit4070 Basel, Switzerland. \\ ICREA, Pg. Lluís Companys 23, 08010 Barcelona, Spain
}

\begin{abstract}
A novel light-induced $\mathrm{C}-\mathrm{H}$ amination of heteroarenes can be accomplished with preformed iodine(III) reagents as the combined oxidant and nitrogen source. The reaction requires the use of a small amount of molecular iodine, which under photochemical activation generates in situ an iodine(I) reagent as the initiator of the radical amination reaction. A total of 32 examples exemplify the broad scope of the transformation.
\end{abstract}

Keywords: Amination; Amidoyl Radicals; $\mathrm{C}-\mathrm{H}$

Functionalization; Iodine; Photochemistry

Aminated heteroarenes constitute an important class of compounds in biological and medicinal chemistry. An appealing general synthetic strategy to the class of aminated heteroarenes consists in the direct $\mathrm{C}-\mathrm{H}$ amination of the free arene precursor. ${ }^{[1]}$ Despite significant progress, predictable regioselectivity still constitutes a major challenge in $\mathrm{C}-\mathrm{H}$ functionalization. With respect to indoles as privileged scaffolds of prominent biological and medicinal importance, selective $\mathrm{C} 2-\mathrm{H}$ amination of this particular substrate has been a domain of transition metal catalysis. ${ }^{[2]}$ In previous exploration of benign metal-free methodology, we could demonstrate that isolated hypervalent iodine reagents $\operatorname{ArI}\left[\mathrm{N}\left(\mathrm{SO}_{2} \mathrm{R}\right)_{2}\right]_{2}$ allow for selective $\mathrm{C} 3$-amination of 2,3-unsubstituted indoles ${ }^{[3,4]}$ while the corresponding C2-position is not accessed (Figure 1). Pursuing a change in regioselectivity to encounter the corresponding $\mathrm{C}-\mathrm{H}$ amination, (radical) catalysis was envisaged. Pioneering work by Maruoka and Studer has explored iodine(III) reagents as precursors for heteroatomcentered radicals. ${ }^{[5,6]}$ Notably, except the special case of azido ${ }^{[6 a]}$ and sulfoximine ${ }^{[6 c]}$ derivatives there is only a single previous literature example on nitrogencontaining iodine(III) reagents affording amination reactions under photochemical conditions, which refers to elegant work on $\mathrm{N}$-acylimidoiodinanes by Takemoto ${ }^{\left[{ }^{[6]}\right]}$ The photochemical functionalization of inert $\mathrm{C}\left(\mathrm{sp}^{2}\right)-\mathrm{H}$ bonds has recently been explored. ${ }^{[7]}$ Highly reactive nitrogen-centered radicals have been involved in many useful organic transformations. ${ }^{[8]}$ When compared to carbon-centered radicals, the synthetic utility of $N$-centered radical species, including neutral $N$-radicals and $N$-radical ions, remains conceptually underdeveloped ${ }^{[8]}$ Visible-light photocatalysis has proven to be a mild tool for the conversion of $\mathrm{N}$-containing compounds into their corresponding highly reactive $N$-radical species,${ }^{[9]}$ and photoredox catalysis has provided an entry to nitrogen radicals by the cleavage of weak $N$-heteroatom bonds. ${ }^{[10,11]}$ As an alternative, the direct oxidation of activated $\mathrm{N}-\mathrm{H}$ bonds can involve stoichiometric reagents. ${ }^{[12]}$ We here report on a novel dual light and iodine induced amidoyl radical formation and its application to the position-selective $\mathrm{C}-\mathrm{H}$ amination of heteroarenes.

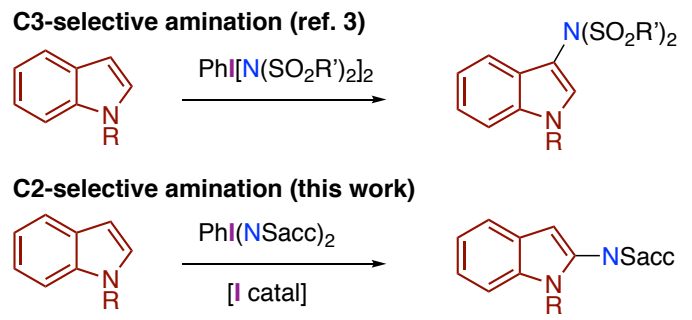

Figure 1. Indole C3 vs. C2 amination with iodine(III) reagents.

$N$-Boc-indole 1a was selected as the substrate and saccharin as the nitrogen source. Saccharin constitutes an interesting pharmaceutical entity in its own right due to its capability for DNA intercalation. ${ }^{[13]}$ Stable iodine(III) reagents have been formed from this heterocycle in the past, ${ }^{[14]}$ and three reagents were considered at the outset. The bis(saccharinato)iodane (2a) could readily be prepared from (diacetoxyiodo)benzene and saccharin on a $31 \mathrm{mmol}$ scale in $88 \%$ yield. The bench stable compound 2 a can be stored without decomposition for months and is characterized here for the first time in its solid state displaying the characteristic T-shaped structure. ${ }^{[15,16]}$ The results obtained for the amidation of $N$-Boc indole (1a) proved to follow a concise trend. In dichloromethane as solvent, catalytic amounts of molecular iodine initiate the selective $\mathrm{C} 2$-amination of 1a to product 3a in the presence of iodine(III) reagent 2a as the combined terminal oxidant and nitrogen source. High amounts of iodine are detrimental for the 
photochemical activation and 8 mol $\%$ was encountered as optimum (entries 1-4). Without iodine, no reaction takes place (entry 5), and alternative iodine sources such as $\mathrm{NBu}_{4} \mathrm{I}$, potassium and sodium iodide give inferior results. ${ }^{[15]}$ Alternative solvents provided lower yields (entries 6-8). Under black LEDs irradiation (entry 9), the same isolated yield as with visible-light (upon exposure to ambient light) was observed. In the latter case 3a was already formed in $54 \%$ yield after $1 \mathrm{~h}$ (entry 10). Also for black LEDs irradiation, the iodine catalyst is required (entry 11). The known cyclic iodine(III) reagent $\mathbf{2 b}$ and its counterpart 2c show comparably lower reactivity (entries 12,13) and were not considered further.

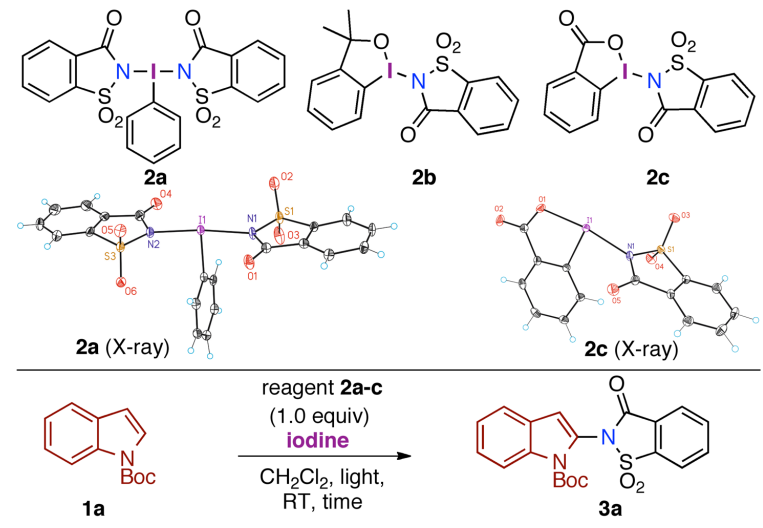

Table 1. Metal-free $\mathrm{C}-\mathrm{N}$ bond formation from $\mathbf{2 a}$ : reaction optimization for $N$-Boc indole $\mathbf{1 a}$.

\begin{tabular}{|c|c|c|c|c|c|}
\hline Entry & Reagent & $\begin{array}{c}\mathrm{I}_{2} \\
{\left[\mathrm{~mol}^{2} \%\right]}\end{array}$ & $\begin{array}{l}\text { Time } \\
{[\mathrm{h}]}\end{array}$ & Light & $\begin{array}{l}\text { Yield } \\
{[\%]^{a)}}\end{array}$ \\
\hline 1 & $2 a$ & 20.0 & 19 & Vis & 38 \\
\hline 2 & $2 a$ & 15.0 & 19 & Vis & 49 \\
\hline 3 & $2 a$ & 8.0 & 19 & Vis & $63^{b)}$ \\
\hline 4 & $2 \mathbf{a}$ & 3.0 & 19 & Vis & 24 \\
\hline 5 & $2 \mathbf{a}$ & - & 19 & Vis & $\mathrm{NR}^{\mathrm{c})}$ \\
\hline 6 & $2 \mathbf{a}$ & 8.0 & 19 & Vis & 12 \\
\hline $7^{\text {d) }}$ & $2 \mathbf{a}$ & 8.0 & 19 & Vis & 22 \\
\hline $8^{e)}$ & $2 \mathbf{a}$ & 8.0 & 19 & Vis & 18 \\
\hline 9 & $2 a$ & 8.0 & 19 & $\begin{array}{l}\text { Black } \\
\text { LED }\end{array}$ & $58^{\mathrm{b})}$ \\
\hline 10 & $2 \mathbf{a}$ & 8.0 & 1 & Vis & 54 \\
\hline 11 & $2 a$ & - & 19 & $\begin{array}{l}\text { black } \\
\text { LED }\end{array}$ & 8 \\
\hline 12 & $2 b$ & 8.0 & 19 & Vis & 16 \\
\hline 13 & $2 c$ & 8.0 & 19 & Vis & 27 \\
\hline
\end{tabular}

b) GC yields using decane as internal standard. ${ }^{b)}$ Isolated yields after purification. ${ }^{\text {c) }} \mathrm{NR}=$ no reaction.

${ }^{d)}$ HFIP as solvent. ${ }^{\text {e) }}$ TFE as solvent.

With the optimized conditions in hand, we evaluated the scope for several indoles (Scheme 1). When the iodine(III) reagent 2a was used, $N$-protected indoles were amidated in moderate to very good yields (products 3a-g). Electron-donating protecting groups such as methyl (3b, 64\%), para-methoxy benzyl (3d, $62 \%$ ) and benzyl (3f, $73 \%$ yield) were superior compared to electron-withdrawing ones. Finally, the aniline $\mathbf{3 b}$ could be readily synthesized on $7.6 \mathrm{mmol}$ scale $(1.5 \mathrm{~g})$, and the C2-amination outcome was additionally confirmed by X-ray analysis. ${ }^{[16]}$ Substituents on the 5-position of the aromatic ring of the indoles were well tolerated as demonstrated for products 3h-l (28-67\%). The same holds true for the 4bromo derivative $\mathbf{3 m}$, which would suffer from selectivity in classical transition-metal-catalyzed Hartwig-Buchwald approaches, and for the product $3 \mathbf{n}$ with a functionalized $N$-alkyl substituent. Introducing a methyl group in the 3-position of the indole does not interfere with $\mathrm{C} 2$-amination (product 3o, 65\%).

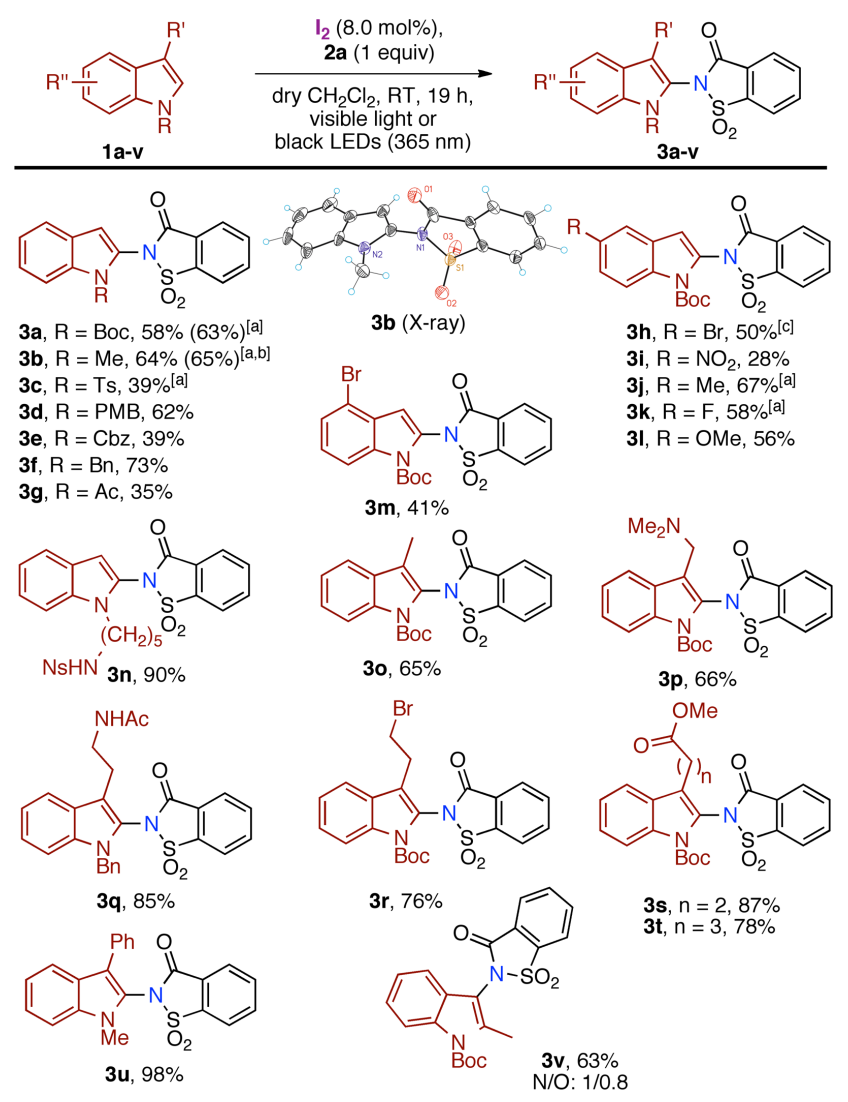

Scheme 1. Photochemical amination of indoles: reaction scope. ${ }^{\text {a) }}$ Visible-light. ${ }^{\text {b) }}$ Reaction on $7.6 \mathrm{mmol}$ scale. ${ }^{\mathrm{c})} 3.0$ equiv. of starting indole derivative.

Compounds with known biological activity such as the herbacide gramine and tryptamine were cleanly aminated to afford $\mathbf{3 p}$ and $\mathbf{3 q}$ in 66 and $76 \%$ yield. Halide and ester functional groups were readily compatible, as demonstrated by compounds 3r-t. The formation of a single derivative $3 \mathbf{u}$ proved that in the presence of a phenyl substituent, the protocol remained fully selective for the indole core. Interestingly, for the case of 2-methylindole $3 \mathbf{v}$ a mixture of $\mathrm{C}-\mathrm{N}$ and $\mathrm{C}-\mathrm{O}$ products with $1 / 0.8$ ratio was observed. This demonstrates the ambident character $^{[14 \mathrm{c}]}$ of the saccharin in the present $\mathrm{C}-\mathrm{H}$ functionalization and may expand the current amination to complimentary oxygenation in future endeavors. As extension of the approach, we took into account the possibility to expand the scope of the reaction to more diversified heterocycles (Scheme 2). 
Under the developed conditions, benzimidazole provided the corresponding aminated compound $\mathbf{5 a}$ in $43 \%$ yield. Interestingly, caffeine, the well-known xanthine alkaloid for stimulation of the central nervous system, furnished $\mathbf{5 b}$ in $56 \%$ yield. This represented a notable enhancement compared to previously reported amination protocols on the same class of substrates. ${ }^{[11 a]}$

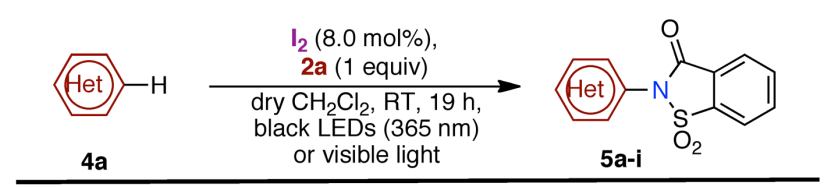<smiles>O=C(O)C1=Nc2ccccc2SN1C1=Nc2ccccc2C1=O</smiles><smiles>Cn1c(=O)c2c(nc(-n3sc4ccccc4c3=O)n2C)n(C)c1=O</smiles>

5a, $43 \%$

5b, 56\%a)

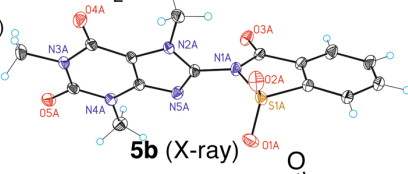<smiles>CC(=O)CCCCn1c(=O)c2c(nc(-n3sc4ccccc4c3=O)n2C)n(C)c1=O</smiles>

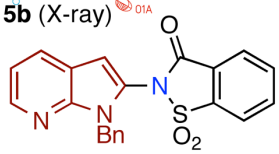<smiles>[R15]c1cc2ncccc2cc1-n1[nH]c2ccccc2c1=O</smiles><smiles>O=CC(=O)N([O-])c1cc2c([nH]1)CCCC2</smiles>

5d, $59 \%$

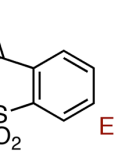<smiles>Cc1ccc(-n2sc3ccccc3c2=O)[nH]1</smiles>

5e, $33 \%$ 5f, $58 \%$

5g, $70 \%$<smiles>O=c1osc2ccccc12</smiles><smiles></smiles>

5i, $43 \%$<smiles></smiles>

5 j, $26 \%$

Scheme 2. Photochemical amination of heterocycles: reaction scope ${ }^{\text {a) }} \mathrm{CHCl}_{3}$ as solvent for better solubilization. b) 3.0 equiv. of starting heterocyclic compound.<smiles>CN(c1nc2c(c(=O)n(C)c(=O)n2C)n1C)n1oc2ccccc2c1=O</smiles>

Scheme 3. Deprotection to free amino caffeine 6.

The structurally related drug pentoxifylline for muscle pain release was equally aminated cleanly to $\mathbf{5 c}$. The substrate scope also includes azaindoles 5d,e. Pyrrole derivatives such as the tetrahydroindole $\mathbf{4 f}$, the ethyl substituted pyrrole $\mathbf{4 g}$ and even free pyrrole $\mathbf{4 h}$ provided the final compounds $\mathbf{5 f}-\mathbf{h}$ in excellent yields, while 2,4-dimethyl pyrrole undergoes aliphatic $\mathrm{C}-\mathrm{H}$ amination to $\mathbf{5 i}$. Also, furan $\mathbf{4} \mathbf{j}$ as a challenging substrate furnished $\mathbf{5} \mathbf{j}$ as a mixture of regioisomers in $26 \%$ yield. As demonstrated for caffeine derivative $\mathbf{5 b}$, quantitative deprotection of the saccharine group to the free amino derivative $\mathbf{6}^{[17]}$ is accomplished under acidic hydrolysis (Scheme 3).

With the bis(saccharinato) iodine(III) reagent 2a representing the combined oxidant and nitrogen source, control experiments were conducted to clarify why the presence of the molecular iodine was necessary at the stage of photoinitiation. In absence of molecular iodine, the amination of $\mathbf{1 a}$ was completely suppressed under visible light, while a mere $8 \%$ product from the background reaction of the reagent 2a was detected under black LED irradiation (Table 1, entries 5,11). This fostered the assumption that the reaction proceeds through radical amination pathways, which is further aided by the exclusive $\mathrm{C}-\mathrm{N}$ formation at $\mathrm{C} 2$, overriding conventional electrophilic amination. A radical close to the lone pair on the indole nitrogen is more stabilized due to the orbital overlap. Additional control experiments ${ }^{[15]}$ with 1a strengthen the assumption of radical pathways. ${ }^{[18]}$

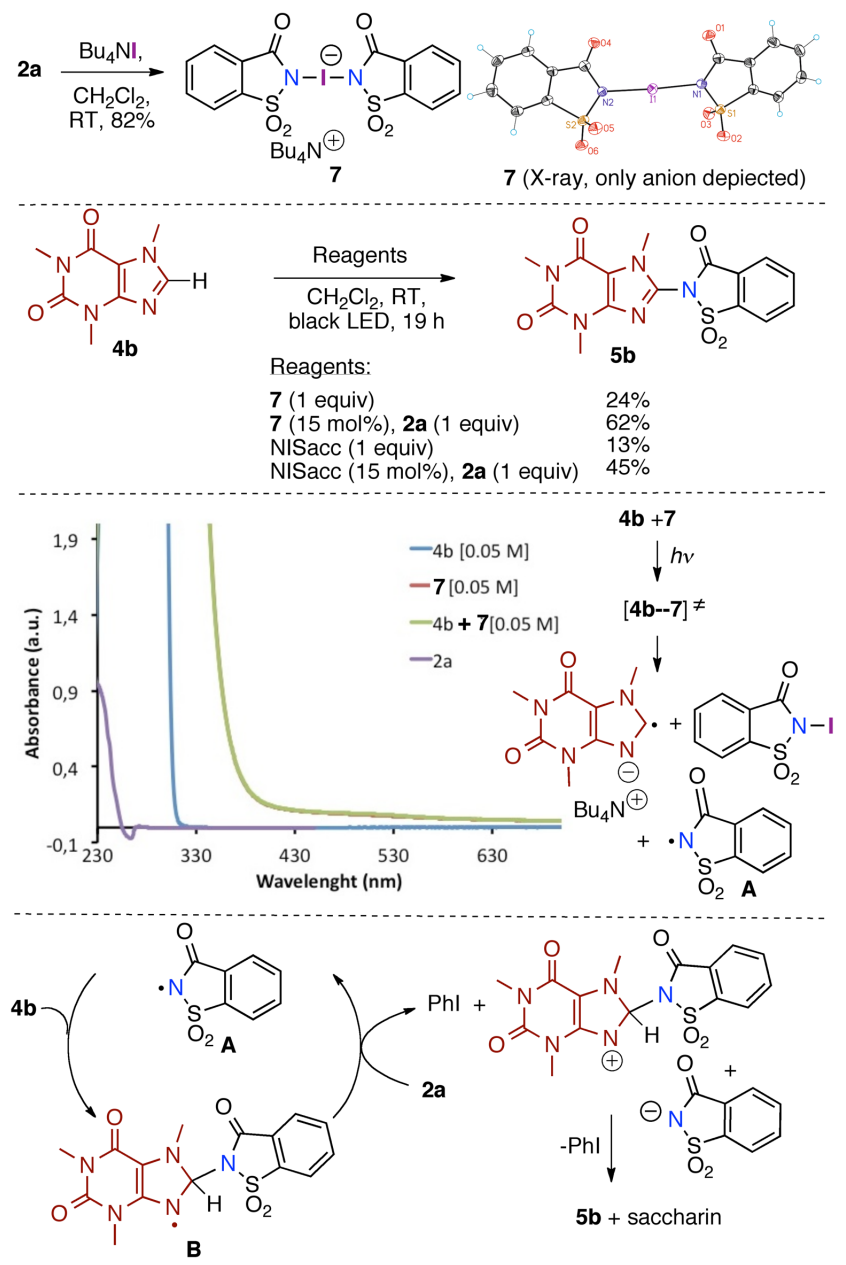

Scheme 4. Control experiments and mechanistic proposal. NISacc $=N$-iodo saccharin.

Subsequently, we proceeded with the synthesis of possible intermediary iodine states to gain understanding on the initiator species. Treatment of $\mathbf{2 a}$ with an equimolar amount of tetrabutylammonium iodide in dichloromethane formed the ionic compound 7 stabilized by the tetrabutylammonium counter ion (Scheme 4). ${ }^{[9]}$ Compound 7 represents a model 
compound for the expected complex iodine derivative $\mathrm{H}\left[\mathrm{I}(\text { Sacch })_{2}\right]$ formed throughout the reaction. ${ }^{[19 a]} \mathrm{We}$ performed two control experiments with 7 for caffeine $\mathbf{4 b}$ as substrate. First, amination of $\mathbf{4 b}$ with iodine(I) reagent 7 provided only a low yield of $\mathbf{5 b}$ of $24 \%$ indicating that 7 or related species do not act as the active reagent in the present transformation. A combination of $15 \mathrm{~mol} \%$ of 7 together with 1 equiv. of iodine(III) reagent $\mathbf{2 a}$ provided $\mathbf{5 b}$ in $62 \%$ yield. Lower yields were observed with neutral $N$-iodo saccharide. In this way, it was confirmed that [I(saccharide $\left.)_{2}\right]^{-}$was playing an active role, although it would not act as a catalyst. The participation of intermediary anionic iodine(I) is thus considered to be that of an initiator of the reaction. This was confirmed by preliminary UV-Vis measurements. The iodine(III) 2a and caffeine $\mathbf{4 b}$ alone revealed an optical absorption at wavelengths that are not compatible with the black LED irradiation at $365 \mathrm{~nm}$. Hence, 2a is excluded as the initial radical source. In contrast, the iodine(I) 7 absorbed at $370 \mathrm{~nm}$, which is in full agreement with the experimental black LEDs conditions $(365 \mathrm{~nm})$. In addition, the absorption profile of the mixture of the two components $\mathbf{7}$ and $\mathbf{4 b}$ was overlapping with the one of 7 . Based on this, it could be assumed that an initial electron transfer between $\mathbf{4 b}$ and 7 gives rise to the initial formation of an $N$-centred saccharin radical A (Scheme 4). This radical promotes selective $\mathrm{C} 2-\mathrm{N}$ bond formation at $\mathbf{4} \mathbf{b}^{[11 a, h, 20]}$ to provide the radical intermediate $\mathbf{B}$, which in turn is oxidized by the iodine(III) reagent 2a. This oxidation regenerates the self-replicating radical carrier $\mathbf{A}$ and provides reduced iodobenzene together with saccharide, which deprotonates the oxidized cationic intermediate to the final product $\mathbf{5 b}$. $^{[21,22]}$

The presented process thus constitutes the proof of concept for photochemically initiated radical $\mathrm{C}-\mathrm{H}$ amination with a defined iodine(III) reagent incorporating iodine-nitrogen bonds. It significantly enlarges the synthetic possibilities of iodine(III) compounds in radical chemistry. In addition, the novel mode of amidoyl generation should provide the reliable basis for future development of related iodineinitiated radical processes for chemical diversification of $\mathrm{C}-\mathrm{H}$ bonds.

\section{Acknowledgements}

We thank Dr. M. Scalone for helpful discussions, and F. HoffmannLa Roche Ltd., the Spanish Ministry for Economy and Competitiveness and FEDER (CTQ2017-88496R grant to K. M., Severo Ochoa Excellence Accreditation 2014-2018 to ICIQ, SEV2013-0319) and the CERCA Program of the Government of Catalonia for financial support.

\section{References}

[1] a) K. Murakami, S. Yamada, T. Kaneda, K. Itami, Chem. Rev. 2017, 117, 9302-9332; b) J. Jiao, K. Murakami, K. Itami, ACS Catal. 2016, 6, 610-633; c) J. A. Leitch, Y. Bhonoah, C. G. Frost, ACS Catal. 2017, 7, 5618-5627; d) Amination and Formation of $\mathrm{sp}^{2} \mathrm{C}-\mathrm{N}$ Bonds, Top. Organomet. Chem. 46 (Eds.: M. Taillefer, D. Ma), Springer, Berlin, Heidelberg, 2012;

[2] Selected recent examples: Rh: a) J. Shi, B. Zhou, Y. Yang, Y. Li, Org. Biomol. Chem. 2012, 10, 8953-8955. Ru: b) J. Wei, W. Xiao, C.-Y. Zhou, C.-M. Che, Chem. Commun. 2014, 50, 3373-3376. Fe: c) K. Foo, E. Sella, I. Thomé, M. D. Eastgate, P. S. Baran, J. Am. Chem. Soc. 2014, 136, 5279-5282. Pd/Cu: d) X.-Y. Liu, P. Gao, Y.W. Shen, Y.-M. Liang, Org. Lett. 2011, 13, 4196-4199. $\mathrm{Cu}$ : e) S. L. McDonald, C. E. Hendrick, Q. Wang, Angew. Chem. Int. Ed. 2014, 53, 4667-4670; Angew. Chem. 2014, 126, 4755-4758; f) H. Yoon, Y. Lee, J. Org. Chem. 2015, 80, 10244-10251; g) X. Wang, K. Sun, Y. Lv, F. Ma, G. Li, D. Li, Z. Zhu, Y. Jiang, F. Zhao, Chem. Asian J. 2014, 9, 3413-3416. Co: h) B. Su, T. Yoshino, S. Matsunaga, M. Kanai, Chem. Commun. 2015, 51, 4659-4661.

[3] L. Fra, A. Millán, J. A. Souto, K. Muñiz, Angew. Chem. Int. Ed. 2014, 53, 7349-7353; Angew. Chem. 2014, 126 , 7477-7481.

[4] K. Muñiz, Acc. Chem. Res. 2018, 51, 1507-1519.

[5] a) R. Sakamoto, T. Inada, S. Selvakumar, S. A. Moteki, K. Maruoka, Chem. Commun. 2016, 52, 3758-3761; b) J. Jiang, R. Ramozzi, S. Moteki, A. Usui, K. Maruoka, K. Morokuma, J. Org. Chem. 2015, 80, 9264-9271; c) S. Selvakumar, R. Sakamoto, K. Maruoka, Chem. Eur. J. 2016, 22, 6552-6555; d) R. Sakamoto, H. Kashiwagi, K. Maruoka, Org. Lett. 2017, 19,5126-5129.

[6] a) X. Wang, A. Studer, Acc. Chem. Res. 2017, 50, 17121724; b) B. Zhang, A. Studer, Org. Lett. 2013, 15, 45484551; c) H. Wang, D. Zhang, C. Bolm, Angew. Chem. 2018, 130, 5965-5968; Angew. Chem. Int. Ed. 2018, 57, 5863-5866; d) Y. Kobayashi, S. Masakado, Y. Takemoto, Angew. Chem. 2018, 130, 701-705; Angew. Chem. Int. Ed. 2018, 57, 693-697.

[7] a) T. Xiong, Q. Zhang, Chem. Soc. Rev. 2016, 45, 30693087; b) Q. Qin, H. Jiang, Z. Hu, D. Ren, S. Yu, Chem. Rec. 2017, 17, 754-774.

[8] a) S. Z. Zard, Chem. Soc. Rev. 2008, 37, 1603-1618; b) R. S. Neale, Synthesis 1971, 1-15; c) L. Stella, Angew. Chem. Int. Ed. 1983, 22, 337-350; Angew. Chem. 1983, 95, 368-380.

[9] For recent reviews, see: a) J.-R. Chen, X.-Q. Hu, L.-Q. Lu, W.-J. Xiao, Chem. Soc. Rev. 2016, 45, 2044-2056; b) M. D. Kärkäs, ACS Catal. 2017, 7, 4999-5022.

[10] a) L. Q. Nguyen, R. R. Knowles, ACS Catal. 2016, 6, 2894-2903; b) E. C. Gentry, R. R. Knowles, Acc. Chem. Res. 2016, 49, 1546-1556; c) D. C. Miller, K. T. Tarantino, R. R. Knowles, Top. Curr. Chem. 2016, 374, 1-59; d) N. A. Romero, K. A. Margrey, N. E. Tay, D. A. Nicewicz, Science 2015, 349, 1326-1330; e) K. A. Margrey, J. B. McManus, S. Bonazzi, F. Zecri, D. A. Nicewicz, J. Am. Chem. Soc. 2017 139, 11288-11299; f) G. B. Boursalian, W. S. Ham, A. R. Mazzotti, T. Ritter, Nature Chem. 2016, 8, 810-815; g) T. Yamaguchi, E. Yamaguchi, A. Itoh, Org. Lett. 2017, 19, 1282-1285. 
[11] For recent examples: a) L. J. Allen, P. J. Cabrera, M. Lee, M. S. Sanford, J. Am. Chem. Soc. 2014, 136, $5607-$ 5610; b) Q. Qin, S. Yu, Org. Lett. 2014, 16, 3504-3507; c) J. Davies, T. D. Svejstrup, D. Fernandez Reina, N. S. Sheikh, D. Leonori, J. Am. Chem. Soc. 2016, 138, 80928095; d) E. Brachet, T. Ghosh, I. Ghosh, B. König, Chem. Sci. 2015, 6, 987-992; e) T. W. Greulich, C. G. Daniliuc, A. Studer, Org. Lett. 2015, 17, 254-257; f) H. Kim, T. Kim, D. G. Lee, S. W. Roh, C. Lee, Chem. Commun. 2014, 50, 9273-9276; g) L. Song, L. Zhang, S. Luo, J.-P. Cheng, Chem. Eur. J. 2014, 20, 14231-14234; h) C. B. Tripathi, T. Ohtani, M. T. Corbett, T. Ooi, Chem. Sci. 2017, 8, 5622-5627; i) T. D. Svejstrup, A. Ruffoni, F. Juliá, V. M. Aubert, D. Leonori, Angew. Chem. 2017, 129, 15144-15148; Angew. Chem. Int. Ed. 2017, 56, 14948-14952; j) S. Das, P. Natarajan, B. König, Chem. Eur. J. 2017, 23, 18161-18165; k) K. A. Margrey, J. B. McManus, S. Bonazzi, F. Zecri, D. A. Nicewicz, J. Am. Chem. Soc. 2017, 139, 11288-11299.

[12] For recent examples: a) Y. Zhao, B. Huang, C. Yang, W. Xia, Org. Lett. 2016, 18, 3326-3329; b) C. Song, H. Yi, B. Dou, Y. Li, A. K. Singh, A. Lei, Chem. Commun. 2017, 53, 3689-3692; c) Y. Zhao, B. Huang, C. Yang, B. Li, B. Gou, W. Xia, ACS Catal. 2017, 7, 2446-2451; d) K. Tong, X. Liu, Y. Zhang, S. Yu, Chem. Eur. J. 2016, 22, 15669-15673; e) C. Martínez, A. E. Bosnidou, S. Allmendinger, K. Muñiz, Chem. Eur. J. 2016, 22, 99299932; f) K. Kiyokawa, T. Kosaka, T. Kojima, S. Minakata, Angew. Chem. 2015, 127, 13923-13927; Angew. Chem. Int. Ed. 2015, 54, 13719-13723.

[13] G. Zhang, L. Wang, X. Zhou, Y. Li, D. Gong, J. Agric. Food Chem. 2014, 62, 991-1000.

[14] a) M. Papadopoulou, A. Varvoglis, J. Chem. Res. (S) 1983, 66-67; b) M. Papadopoulou, A. Varvoglis, $J$. Chem. Res. (S) 1984, 166-167; c) A. Yoshimura, S. R. Koski, J. M. Fuchs, A. Saito, V. N. Nemykin, V. V. Zhdankin, Chem. Eur. J. 2015, 21, 5328-5331.

[15] Details are provided in the Supporting Information.

[16] Details on the X-ray crystallographic data for compounds 2a, 2c, 3b, 5b and $\mathbf{6}$ have been deposited with the Cambridge Crystallographic Data Centre database (http://www.ccdc.cam.ac.uk/) under codes CCDC 1578646 (2a), 1578647 (2c), 1578648 (3b), 1578649 (5b), and 1578650 (7), respectively.
[17] M. A. Mosselhi, W. Pfleiderer, W. Helv. Chim. Acta 2010, 93, 2115-2134.

[18] The same conclusion was reached by Togo and Yokoyama for a reaction under overstoichiometric conditions: H. Togo, Y. Hoshina, T. Muraki, H. Nakayama, M. Yokoyama, J. Org. Chem. 1998, 63, 5193-5200.

[19] a) C. Martínez, K. Muñiz, Angew. Chem. Int. Ed. 2015, 54, 8287-8291; Angew. Chem. 2015, 127, 8405-8409; b) K. Muñiz, B. García, C. Martínez, A. Piccinelli, Chem. Eur. J. 2017, 23, 1539-1545; c) A. Kirschning, H. Monenschein, C. Schmeck, Angew. Chem. Int. Ed. 1999, 38, 2594-2596; Angew. Chem. 1999, 111, 2720-2722; d) A. Kirschning, A. Hashem, H Monenschein, L. Rose, K.-U. Schöning, J. Org. Chem. 1999, 64, 6522-6526; e) S. Domann, G. Sourkouni-Argirusi, N. Merayo, A. Schönberger, A. Kirschning, Molecules 2001, 6, 61-66.

[20] For recent examples of xanthine functionalization: a) P. Gao, Y.-R. Gu, X.-H. Duan, Synthesis 2017, 49, 34073421; b) M. Yan, J. C. Lo, J. T. Edwards, P. S. Baran, J. Am. Chem. Soc. 2016, 138, 12692-12714; c) A. G. O'Brien, A. Maruyama, Y. Inokuma, M. Fujita, P. S. Baran, D. G. Blackmond, Angew. Chem. Int. Ed. 2014, 53, 11868-11871; Angew. Chem. 2014, 126, 1206212065; d) T. Kawakami, K. Murakami, K. Itami, J. Am. Chem. Soc. 2015, 137, 2460-2463.

[21] As a result, this mechanism differs from a related stoichiometric transformation under thermal conditions: F. Zhao, T. Sun, H. Sun, G. Xi, K. Sun, Tetrahedron Lett. 2017, 58, 3132-3135.

[22] At present, a definite uniform mechanism for all substrates including electron-rich indols $\mathbf{1}$ requires additional studies. While ionic pathways cannot be rules out for these compounds, they appear inconsistent with the observation that related $\mathrm{N}$-iodinated amides do not display any reactivity similar to saccharine. ${ }^{[15]}$ 


\section{COMMUNICATION}

Radical C-H-Amination of Heteroarenes using Dual Initiation by Visible Light and Iodine

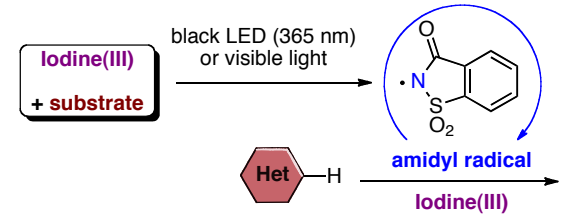

Adv. Synth. Catal. Year, Volume, Page - Page

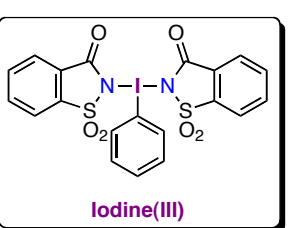

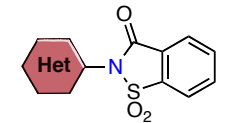

32 examples, complete regioselectivity

Nicola Lucchetti, Anastasia Tkacheva, Serena Fantasia, and Kilian Muñiz* 